\title{
Clinical Application of Transient Elastography in the Diagnosis of Liver Fibrosis: an Expert Panel Review and Opinion
}

\author{
Expert Panel on Liver Stiffness Measurement
}

\begin{abstract}
Liver fibrosis evaluation is pivotal for treatment decisions and prognosis assessment in patients with chronic liver disease. Liver transient elastography (TE) is a newly developed noninvasive technique for diagnosis of liver fibrosis. It can assess the state of liver fibrosis by liver stiffness measurements, and offers better performance for the diagnosis of liver cirrhosis than serum biological markers. It has now been approved for clinical use in China. The aim of this review is to provide a guide for clinicians to apply this technique appropriately. The recommendations are made under the auspices of China Foundation for Hepatitis Prevention and Control, and have been prepared by a panel experts, who have reviewed and summarized the clinical studies on TE in order to develop these recommendations.

(c) 2014 The Second Affiliated Hospital of Chongqing Medical University. Published by XIA \& HE Publishing Ltd. All rights reserved.
\end{abstract}

\section{Introduction}

It is well established that many patients with chronic hepatitis and even early cirrhosis may have no specific symptoms, signs, or biochemical abnormallities. Once symptoms or signs are detected, most cases already have well-established liver cirrhosis, and even hepatic failure. Timely assessment and detection of advanced liver fibrosis and early diagnosis of cirrhosis are critical steps in managing chronic liver disease. The use of liver biopsy, the current "gold standard" for diagnosis of liver fibrosis/cirrhosis, suffers from limitations such as low acceptability, invasiveness, risks of repeated sampling, sampling error, and inter-observer and intraobserver variability. Therefore, it is important to develop non-invasive diagnostic techniques for the diagnosis of liver fibrosis.

Keywords: Transient elastography; Liver fibrosis; Diagnosis; Expert opinion. Abbreviations: AUC, area under receiver operating characteristics curve; AUROC, area under the receiver operating characteristic curve; CCI, Compensated Cirrhosis Index; CHB, chronic hepatitis B; LSM, liver stiffness measurement; NLR, negative likelihood ratio; NPV, negative predictive value; PLR, positive likelihood ratio; PPV, positive predictive value; TE, transient elastography.

Received: 17 February 2014; Revised: 24 May 2014; Accepted: 30 May 2014

DOI of original article: 10.14218/JCTH.2014.00008.

Correspondence to: Jin-Lin Hou, Department of Infectious Disease and Hepatology Unit, Nanfang Hospital, Southern Medical University, Guangzhou 510515, China. Email: jlhou@smu.edu.cn; Ji-Dong Jia, Liver Research Center, Beijing Friendship Hospital, Capital Medical University, Beijing 100050, China. Email: jiamd@263.net
Liver transient elastography (TE) is a newly developed non-invasive technique for diagnosis of liver fibrosis. It can be used to assess the state of liver fibrosis by liver stiffness measurement (LSM). TE techniques (for example, Fibroscan) offer better diagnostic performance for liver cirrhosis than serum biological markers including FibroTest, FibroMeter, HepaScore, APRI, API, FIB-4, Forns Index, Hui Index, and Compensated Cirrhosis Index (CCI) ${ }^{1-7}$ and it has been approved for clinical use in China. To assist in the optimal application of this technique in clinical practice, the China Foundation for Hepatitis Prevention and Control has brought together experts to develop Expert Opinions on the Diagnosis of Liver Fibrosis with Transient Elastography. The panel discussed and finalized the draft in November 2012 based on progress in clinical practice, and growing evidence in the field.

\section{The statistical basis for assigning cutoff values}

Ideally, the diagnostic cutoff values of non-invasive diagnosis should have a high negative predictive value (NPV) and low negative likelihood ratio (NLR) to rule out a diagnosis as well as a high positive predictive value (PPV) and high positive likelihood ratio (PLR) to confirm a diagnosis. There are necessary in order to avoid mis-diagnosis of liver fibrosis or missed diagnosis of advanced fibrosis and cirrhosis. To ensure the accuracy of the diagnosis, it is necessary to adopt low cutoffs to exclude the diagnosis and high cutoffs to confirm the diagnosis. When the measured values fall in the gray zone between the high and low cutoffs, liver biopsy is still necessary. ${ }^{8-9}$ Statistical analysis showed that cutoff values with a PLR $>10.0$ afford sufficient confidence to confirm the diagnosis, whereas cutoff values with a NLR $<0.1$ provide enough confidence to rule out a disease. Therefore, the determination of high and low cutoff values should meet these special requirements.

Recommendations for the application of TE in noninvasive diagnosis of liver fibrosis

\section{Operational requirements}

The operation of TE is mainly affected by obesity and narrow intercostal space. TE usually fails in patients with ascites. Operational failure or unreliable test results are independently associated with operator experience of $<500$ examinations and patient characteristics of BMI $>30 \mathrm{~kg} / \mathrm{m}^{2}$, age $>$ 52 years, female gender, hypertension, and type 2 diabetes. ${ }^{10}$ Abdominal obesity (abdominal circumference $>$ $80 \mathrm{~cm}$ in women and $>90 \mathrm{~cm}$ in men) is also an independent 
risk factor for operational failure or unreliable results. ${ }^{11}$ In patients with BMI $\geqslant 28.0 \mathrm{~kg} / \mathrm{m}^{2}$, and an abdominal circumference $\geqslant 102 \mathrm{~cm}$, an XL probe yields higher success rates than the $M$ probe. ${ }^{12-13}$ An $X L$ probe can generate reliable results in $51.6-61 \%$ of patients for whom the $M$ probe is unable to obtain reliable detection results. ${ }^{12-14}$ The $S$ probe is suitable for patients with narrow intercostal space and children. However this probe is associated with significantly higher failure rates in children under 5 years of age. ${ }^{15}$ It remains to be determined whether there are differences in the detection results obtained with the $S$ probe or the $M$ probe. The reliability of LSM depends mainly on the ratio of the interquartile range, and the median of detection values $(\mathrm{IQR} / \mathrm{M})$, where IQR/M $\leqslant 0.10$ suggests very reliable results, $0.10<\mathrm{IQR} / \mathrm{M} \leqslant 0.30$ or IQR/M $>0.30$ with median $\mathrm{LSM}<$ $7.1 \mathrm{kPa}$ suggests reliable results, and IQR/M $>0.30$ and median LSM $\geqslant 7.1 \mathrm{kPa}$ suggest unreliable results. ${ }^{16}$

Recommendation 1: TE operators should receive standard training and have relatively constant annual volumes of cases to ensure the reliability of test results.

Recommendation 2: The M probe should be the first choice for TE measurements. For overweight or obese patients from whom TE cannot obtain reliable results, the XL probe may be considered. The S probe may be considered for patients with narrow intercostal space or for children.

Recommendation 3: Test results must meet all the following conditions to be considered valid: at least 10 valid tests, success rate $>60 \%$, and IQR/M $<0.3$.

\section{Influencing factors}

LSM is influenced by factors such as hepatic necroinflammatory activity (manifested as elevated levels of transaminases or bilirubin), ${ }^{17-18}$ extrahepatic cholestasis, ${ }^{19-20}$ hepatic venous congestion, ${ }^{21-22}$ and food intake, ${ }^{23-24}$ and LSM decreases along with reductions in ALT and bilirubin levels. ${ }^{17-18}$

Recommendation 4: TE should be performed after fasting or at least 2 hours postprandially, and ALT and bilirubin levels should be considered to make a hierarchical diagnosis. Extrahepatic cholestasis and heart failure should be ruled out.

\section{Normal reference values}

The normal reference ranges in healthy living liver donors and kidney donors in South Korea have been reported to be $3.7-7.0 \mathrm{kPa}$ in men, and $3.3-6.8 \mathrm{kPa}$ in women. ${ }^{25}$ Normal LSM values of adult male residents without notable liver disease in Guangdong have been found to vary with age (age $<60$ years: $5.2 \pm 1.3 \mathrm{kPa}$; age $\geqslant 60$ years: $5.9 \pm$ $1.8 \mathrm{kPa}) .{ }^{26}$ The normal reference range in a South Asia population was found to be $3.2-8.5 \mathrm{kPa}$, and lean or obese people have higher values than those with normal BMIs. ${ }^{27}$ The normal reference range in people with no significant liver disease in Hong Kong was found to be $2.8-7.4 \mathrm{kPa}^{28}$ Because the number of individuals with high BMI who develop fatty liver in the population is increasing, and it is not grouped into the liver disease population, current normal reference values do not take into account for the impact of high BMIs.

Recommendation 5: The normal reference range of LSM should be $2.8-7.4 \mathrm{kPa}$.

\section{Diagnostic cutoff values}

A. Chronic hepatitis B:

The area under the receiver operating characteristic curve (AUROC) values for significant liver fibrosis (Metavir $F \geqslant 2$ ), advanced liver fibrosis $(F \geqslant 3)$, and cirrhosis $(F=4)$ due to chronic hepatitis $B(C H B)$ were $0.78-0.87,0.87-0.93$, and $0.84-0.96$, respectively (Table 1$)^{7,29-33}$ It is possible to determine whether cirrhosis is present in more than $78 \%$ of patients with normal bilirubin levels, and whether advanced liver fibrosis is present in $80 \%$ of these patients. Increased bilirubin levels exert a significant impact on the diagnostic performance of TE: only $41 \%$ of patients can be identified as having cirrhosis, and $53 \%$ can be identified as having advanced liver fibrosis. 7,33 The diagnostic performance of TE at cutoff values of $10.1 \mathrm{kPa}$ (NLR 0.15 and PLR 7.3), $12.9 \mathrm{kPa}$ (PLR 7.33, NLR 0.52), 14.1 kPa (PLR 5.6, NLR 0.19), and $11 \mathrm{kPa}$ (PLR 7.3, NLR 0.28) is unsatisfactory for diagnosis of liver cirrhosis in patients with normal ALT levels, 5,35-36 suggesting that the cutoff value for confirming cirrhosis should be higher than $14.1 \mathrm{kPa}$, and the cutoff value for excluding cirrhosis should be less than $11 \mathrm{kPa}$. At cutoff values of $10.2 \mathrm{kPa}$ and $8.1 \mathrm{kPa}, \mathrm{NLR}$ values were 0.15 and 0.15 , and PLR values were 9.0 and 4.6 , respectively, for the diagnosis of advanced liver fibrosis, ${ }^{35-36}$ suggesting that the high cutoff value for advanced liver fibrosis should be slightly higher than $10.2 \mathrm{kPa}$, while the lower cutoff value should be less than $8.1 \mathrm{kPa}$. Most cutoff values that help establish the diagnosis of significant liver fibrosis offer no clinical value due to a PLR $<5.0$ or NLR $>0.2 .^{5,29,34-36}$

Recommendation 6: In patients with abnormal bilirubin levels, LSM $\geqslant 29.2 \mathrm{kPa}$ suggests cirrhosis, LSM $\geqslant 17.0 \mathrm{kPa}$ suggests advanced liver fibrosis, LSM $<9.1 \mathrm{kPa}$ excludes cirrhosis, and LSM $<7.8 \mathrm{kPa}$ excludes advanced liver fibrosis. Patients with LSM values in the grey zone can be measured again after bilirubin levels return to normal, using normal bilirubin cutoffs for diagnosis, or will require liver biopsy.

Recommendation 7: In patients with normal bilirubin levels, LSM $\geqslant 17.5 \mathrm{kPa}$ suggests cirrhosis, LSM $\geqslant 12.4 \mathrm{kPa}$ (10.6 kPa if ALT $<2 \times$ upper normal limit) suggests advanced liver fibrosis, LSM $<10.6 \mathrm{kPa}$ rules out cirrhosis, LSM $\geqslant$ $9.4 \mathrm{kPa}$ suggests significant fibrosis, and LSM $<7.4 \mathrm{kPa}$ rules out advanced liver fibrosis. If clinical decision-making is difficult for patients with LSM between 7.4-9.4 kPa, a liver biopsy should be considered.

Recommendation 8: In patients with normal aminotransferase levels, LSM $\geqslant 12.0 \mathrm{kPa}$ suggests cirrhosis, LSM $\geqslant$ $9.0 \mathrm{kPa}$ suggests advanced liver fibrosis, LSM $<9.0 \mathrm{kPa}$ rules out cirrhosis, and LSM $<6.0 \mathrm{kPa}$ rules out advanced liver fibrosis. If clinical decision-making is difficult for patients with LSM between $6.0-9.0 \mathrm{kPa}$, a liver biopsy should be considered.

Given the significant impact of abnormal bilirubin levels on the diagnostic performance of $\mathrm{TE}$, the measurement should be performed when bilirubin levels return to normal, and interventions may be taken based on clinical virology data as shown in Fig. 1.

B. Chronic hepatitis C:

The AUROC of LSM for hepatitis C cirrhosis is $0.90-$ $0.97^{2,5,37-39}$ (Table 2), which is better than that for other non-invasive diagnostic modalities of liver fibrosis including FibroTest, APRI, Lok index, platelet count, and AST/ALT ratio. ${ }^{38}$ In a large sample study $(n=913)$, the NLR and PLR 


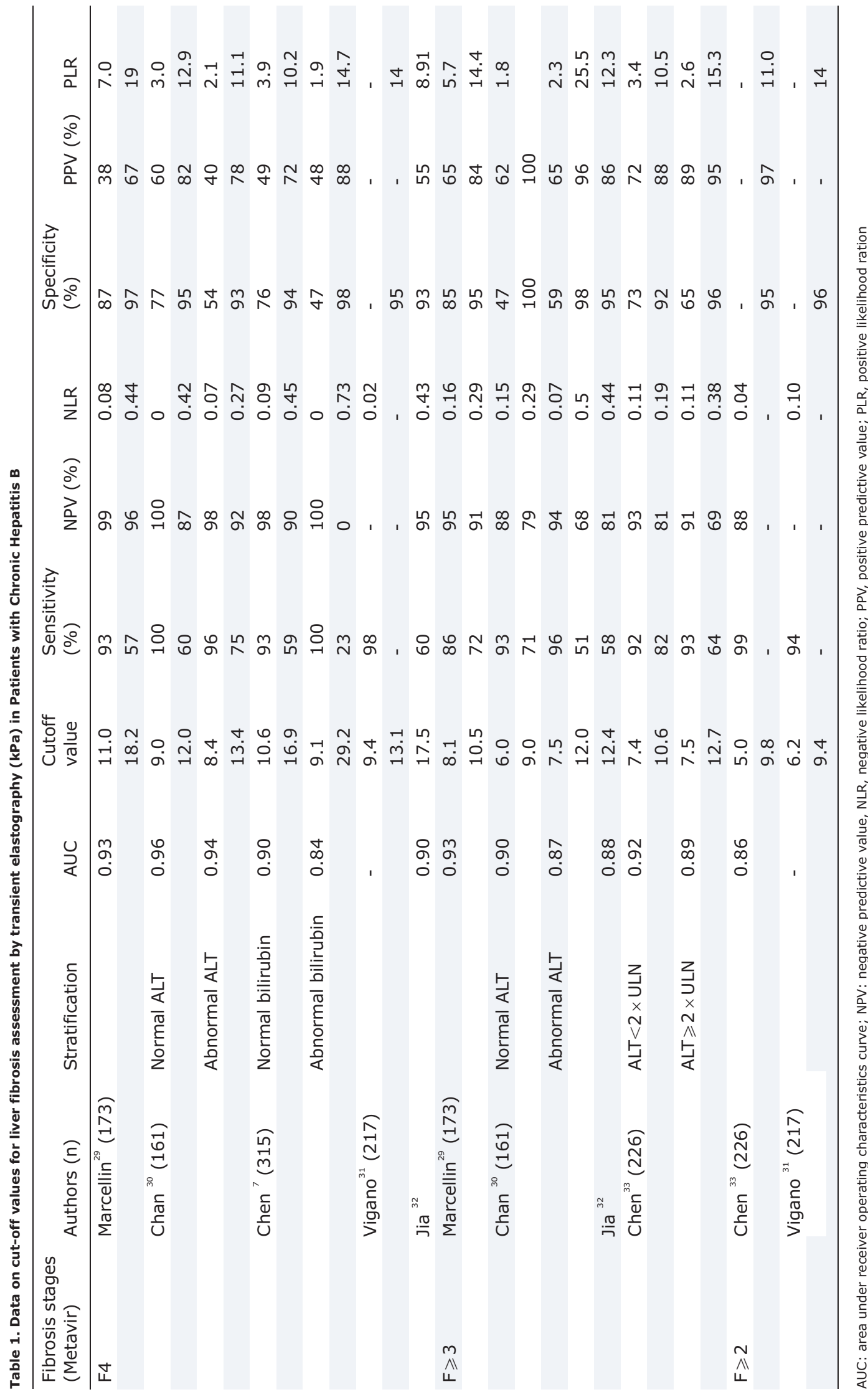




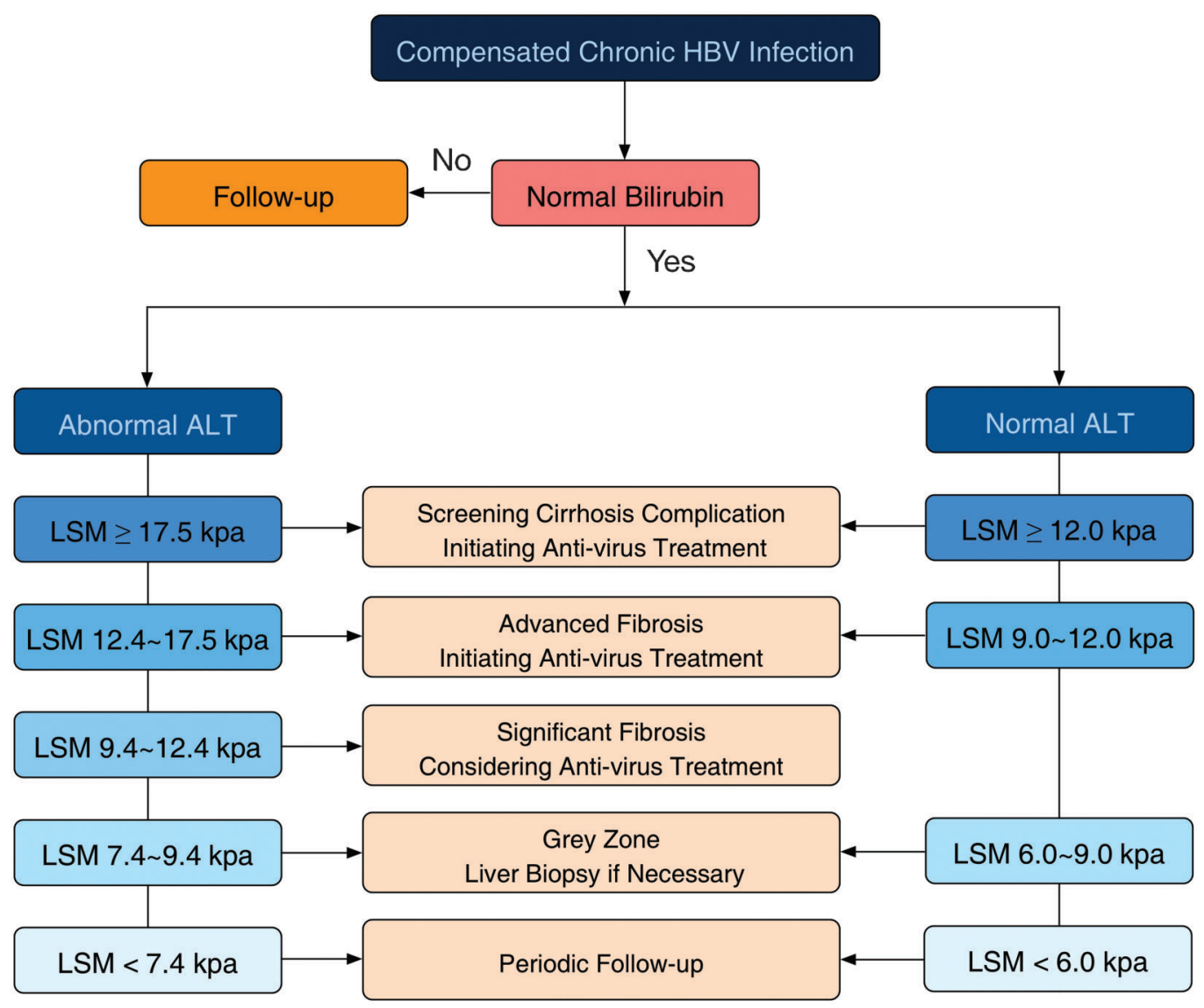

Fig. 1 Transient elastography for diagnosis of patients with HBV virus infection at different stages of liver fibrosis

were 0.31 and 6.77 , respectively, at the recommended cutoff value of $12.9 \mathrm{kPa}$, suggesting the cutoff value for confirmative diagnosis of cirrhosis should be higher than $12.9 \mathrm{kPa} .{ }^{5} \mathrm{At}$ a cutoff value of $14.6 \mathrm{kPa}$, the PLR was as high as 21.5 , confirming the diagnosis of cirrhosis. The cutoff values for significant fibrosis suggested by a number of studies provide insufficient evidence to confirm or exclude the diagnosis of significant fibrosis (Table 2), and the cutoff values for confirmative diagnosis of significant fibrosis should be higher than $7.1 \mathrm{kPa}$.

Recommendation 9: LSM $\geqslant 14.6 \mathrm{kPa}$ suggests cirrhosis, whereas LSM $<9.3 \mathrm{kPa}$ excludes cirrhosis. LSM $\geqslant 9.3 \mathrm{kPa}$ suggests advanced liver fibrosis, whereas LSM $<7.3 \mathrm{kPa}$ rules out advanced liver fibrosis. LSM $\geqslant 7.3 \mathrm{kPa}$ suggests significant fibrosis.

\section{Non-alcoholic fatty liver disease}

The diagnostic performance of TE for advanced fibrosis and cirrhosis in non-alcoholic fatty liver is superior to AST/ALT ratio, APRI, FIB-4, BARD and NAFLD fibrosis scores, and other non-invasive serum markers, with AUROC values of TE for $\geqslant F 2, \geqslant F 3$, and F4 liver fibrosis being 0.84, 0.93, and 0.95, respectively. The NLR was 0.12 at a cutoff value of $7.9 \mathrm{kPa}$ for the diagnosis of $\geqslant F 3$ fibrosis, and 0.09 at a cutoff value of $10.3 \mathrm{kPa}$ for the diagnosis of cirrhosis. The PLR was 8.9 at a cutoff value of $9.6 \mathrm{kPa}$ for the diagnosis of $\geqslant \mathrm{F} 3$ fibrosis. ${ }^{40}$ Measured LSM valuses obtained with the XL probe are lower than those obtained with the M probe ( $6.8 \mathrm{kPa} v s .7 .8 \mathrm{kPa}){ }^{12}$ and the diagnostic cutoffs of the $\mathrm{M}$ probe differed by $1-2 \mathrm{kPa}$ from those of the $\mathrm{XL}$ probe. ${ }^{13}$

Recommendation 10: Advanced liver fibrosis may be considered for patients with LSM $\geqslant 9.8 \mathrm{kPa}$, and clinical intervention should be taken. Patients with LSM between 7.9$9.8 \mathrm{kPa}$ need to undergo liver biopsy to determine the stage of liver fibrosis. Patients with LSM $<7.9 \mathrm{kPa}$ should receive regular LSM monitoring and BMI reduction intervention.

Recommendations 11: The XL probe may be considered in patients who fail using the $M$ probe, and the diagnostic cutoff value should be lowered by $1-2 \mathrm{kPa}$.

All the recommended diagnostic cutoff values for various liver diseases are summarized in Table 3.

\section{Prospects of clinical application of TE}

In the course of antiviral therapy, LSM decline does not solely reflect the reversal of liver fibrosis. It is also associated with decreased necroinflammation scores. ${ }^{41}$ Various antiviral drugs may exert different effects on improving liver necroinflammation, and further studies are needed to determine the cutoff values of TE for determining liver fibrosis stages in patients receiving antiviral therapy. A large-scale, community-based study that included 1190 patients over 45 years of age showed that 89 patients with LSM $>8 \mathrm{kPa}$ (of whom nine had LSM $>13 \mathrm{kPa}$ ) had a certain chronic liver disease, and that liver biopsy confirmed the presence of liver cirrhosis in the nine patients with LSM $>13 \mathrm{kPa},{ }^{42}$ suggesting that TE can 
Expert Panel on Liver Stiffness Measurement: TE in the diagnosis of liver fibrosis
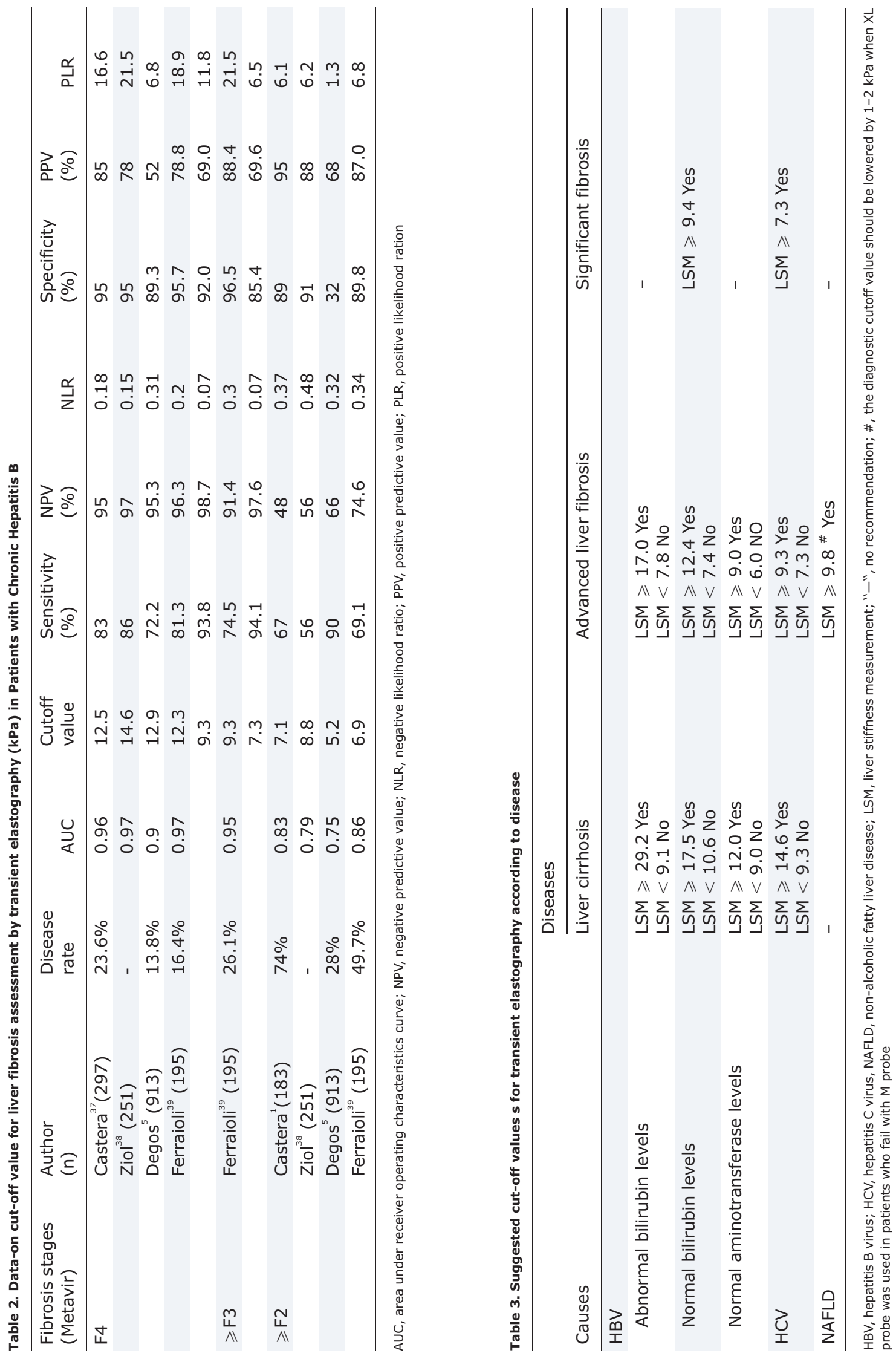
identify liver cirrhosis, and reveal previously undiagnosed chronic liver disease in the general population. The increase in LSM is associated with higher risk of hepatocellular carcinoma development, ${ }^{43-44}$ but there is no reliable cutoff value for the prediction of hepatocellular carcinoma. The AUROC of LSM for the prediction of hepatic decompensation is $0.90-0.92$, and the AUROC of LSM for the prediction of ChildPugh C cirrhosis is $0.91 .^{45-46}$ However, further research is required to establish the predictive value of LSM for the progression of liver disease. High-risk esophageal varices (moderate and severe grade, mild grade with liver decompensation) require early clinical intervention to prevent bleeding. However, LSM offers limited value for prediction of high-risk esophageal varices (AUROC, 0.71-0.73), ${ }^{47-48}$ and the combined use of LSM and other non-invasive indicators seems to improve the predictive performance. ${ }^{47,49-50}$

As TE measurements are affected by many factors, this technique may produce diagnoses inconsistent with other diagnostic methods. For example, liver cirrhosis with mild necroinflammation can present a low LSM. When different non-invasive diagnostic methods produce inconsistent diagnoses, abdominal ultrasography, platelet count, and other clinical data can also be analyzed to help establish a definite diagnosis. For patients in whom a definite diagnosis cannot be reached due to TE values in the gray zone, serum biomarkers may provide complementary diagnostic parameters. When used in combination with TE, serum biomarkers, and imaging examinations (sequential or parallel diagnosis), the consequence of misdiagnosis or missed diagnosis should be considered. Sequential measurements raises the sensitivity, but may lead to higher misdiagnosis rates due to lower specificity, whereas parallel measurements can increase specificity and increase diagnostic reliability, but may also increase the risk of missed diagnosis by reducing sensitivity.

Liver stiffness assessment expert panel: Zhuang Hui, Hou Jinlin, Jia Jidong, Wei Lai, Ren Hong, Wang Guiqiang, Lu Lungen, Fan Jiangao, Niu Junqi, Xie Qing, Ning Qin, Dou Xiaoguang, Li Jie, Ma Hong, You Hong, Shu Jianchang, and Chen Yongpeng (secretary).

\section{Conflict of interest}

None

\section{Author contributions}

Writing the paper (all authors).

\section{References}

[1] Castéra L, Vergniol J, Foucher J, Le Bail B, Chanteloup E, Haaser M, et al. Prospective comparison of transient elastography, Fibrotest, APRI, and liver biopsy for the assessment of fibrosis in chronic hepatitis C. Gastroenterology 2005;128:343-350. doi: 10.1053/j.gastro.2004.11.018.

[2] Shaheen AA, Wan AF, Myers RP. FibroTest and FibroScan for the prediction of hepatitis C-related fibrosis: a systematic review of diagnostic test accuracy. Am J Gastroenterol 2007;102:2589-2600. doi: 10.1111/j.15720241.2007.01466.x.

[3] Kim SU, Ahn SH, Park JY, Kang W, Kim do Y, Park YN, et al. Liver stiffness measurement in combination with noninvasive markers for the improved diagnosis of B-viral liver cirrhosis. J Clin Gastroenterol 2009;43:267-271. doi: 10.1097/MCG.0b013e31816f212e.

[4] Wong GL, Wong VW, Choi PC, Chan AW, Chan HL. Development of a noninvasive algorithm with transient elastography (Fibroscan) and serum test formula for advanced liver fibrosis in chronic hepatitis B. Aliment Pharmacol Ther 2010;31:1095-1103. doi: 10.1111/j.1365-2036.2010.04276.x.

[5] Degos F, Perez P, Roche B, Mahmoudi A, Asselineau J, Voitot $H$, et al. Diagnostic accuracy of FibroScan and comparison to liver fibrosis biomarkers in chronic viral hepatitis: a multicenter prospective study (the FIBROSTIC study). J Hepatol 2010;53:1013-1021. doi: 10.1016/j.jhep.2010.05.035.

[6] Poynard T, Ngo Y, Munteanu M, Thabut D, Ratziu V. Noninvasive markers of hepatic fibrosis in chronic hepatitis B. Curr Hepat Rep 2011;10:87-97. doi: 10.1007/s11901-011-0096-0.

[7] Chen YP, Liang XE, Dai L, Zhang Q, Peng J, Zhu YF, et al. Improving transient elastography performance for detecting hepatitis B cirrhosis. Dig Liver Dis 2012;44:61-66. doi: 10.1016/j.dld.2011.08.004.

[8] Sebastiani G, Alberti A. Non-invasive fibrosis biomarkers reduce but not substitute the need for liver biopsy. World J Gastroenterol 2006;12:36823694.

[9] Manning DS, Afdhal NH. Diagnosis and quantitation of fibrosis.Gastroenterology 2008;134:1670-1681. doi: 10.1053/j.gastro.2008.03.001

[10] Castéra L, Foucher J, Bernard PH, Carvalho F, Allaix D, Merrouche W, et al. Pitfalls of liver stiffness measurement: a 5-year prospective study of 13369 examinations. Hepatology 2010;51:828-835.

[11] Wong GL, Wong VW, Chim AM, Yiu KK, Chu SH, Li MK, et al. Factors associated with unreliable liver stiffness measurement and its failure with transient elastography in the Chinese population. J Gastroenterol Hepatol 2011;26:300-305. doi: 10.1111/j.1440-1746.2010.06510.x.

[12] Myers RP, Pomier-Layrargues G, Kirsch R, Pollett A, Duarte-Rojo A, Wong D, et al. Feasibility and diagnostic performance of the FibroScan XL probe for liver stiffness measurement in overweight and obese patients. Hepatology 2012;55:199-208. doi: 10.1002/hep.24624.

[13] Wong VW, Vergniol J, Wong GL, Foucher J, Chan AW, Chermak F, et al. Liver stiffness measurement using $\mathrm{XL}$ probe in patients with nonalcoholic fatty liver disease. Am J Gastroenterol 2012;107:1862-1871.

[14] de Lédinghen V, Wong VW, Vergniol J, Wong GL, Foucher J, Chu SH, et al. Diagnosis of liver fibrosis and cirrhosis using liver stiffness measurement: comparison between M and XL probe of FibroScan. J Hepatol 2012;56:833839. doi: $10.1016 /$ j.jhep.2011.10.017.

[15] Engelmann G, Gebhardt C,Wenning D, Wühl E, Hoffmann GF, Selmi B, et al. Feasibility study and control values of transient elastography in healthy children. Eur J Pediatr 2012;171:353-360.

[16] Boursier J, Zarski JP, de Ledinghen V, Rousselet MC, Sturm N, Lebail B, et al. Determination of reliability criteria of liver stiffness evaluation by transient elastography. Hepatology 2013;57:1182-1191. doi: 10.1002/hep.25993.

[17] Liang XE, Chen YP, Zhang Q, Dai L, Zhu YF, Hou JL, et al. Dynamic evaluation of liver stiffness measurement to improve diagnostic accuracy of liver cirrhosis in patients with chronic hepatitis B acute exacerbation. J Viral Hepat 2011;18:884-891. doi: 10.1111/j.1365-2893.2010.01389.x

[18] Wong GL, Wong VW, Choi PC, Chan AW, Chim AM, Yiu KK, et al. Increased liver stiffness measurement by transient elastography in severe acute exacerbation of chronic hepatitis B. J Gastroenterol Hepatol 2009;24 1002-1007. doi: 10.1111/j.1440-1746.2009.05779.x.

[19] Harata M, Hashimoto S, Kawabe N, Nitta Y, Murao M, Nakano T, et al. Liver stiffness in extrahepatic cholestasis correlates positively with bilirubin and negatively with alanine aminotransferase. Hepatol Res 2011;41:423-429. doi: 10.1111/j.1872-034X.2011.00797.x.

[20] Millonig G, Reimann FM, Friedrich S, Fonouni H, Mehrabi A, Büchler MW, et al. Extrahepatic cholestasis increases liver stiffness (FibroScan) irrespective of fibrosis. Hepatology 2008;48:1718-1723. doi: 10.1002/hep.22577.

[21] Colli A, Pozzoni P, Berzuini A, Gerosa A, Canovi C, Molteni EE, et al. Decompensated chronic heart failure: increased liver stiffness measured by means of transient elastography. Radiology 2010;257:872-878. doi: 10.1148/radiol.10100013.

[22] Millonig G, Friedrich S, Adolf S, Fonouni H, Golriz M, Mehrabi A, et al. Liver stiffness is directly influenced by central venous pressure. J Hepatol 2010; 52:206-210. doi: 10.1016/j.jhep.2009.11.018.

[23] Mederacke I, Wursthorn K, Kirschner J, Rifai K, Manns MP, Wedemeyer $\mathrm{H}_{\text {, }}$ et al. Food intake increases liver stiffness in patients with chronic or resolved hepatitis C virus infection. Liver Int 2009;29:1500-1506. doi: 10.1111/ j.1478-3231.2009.02100.x.

[24] Arena U, Platon ML, Stasi C, Moscarella S, Assarat A, Bedogni G, et al. Liver stiffness is influenced by a standardized meal in patients with chronic hcv hepatitis at different stages of fibrotic evolution. Hepatology 2013;58:6572. doi: 10.1002/hep.26343.

[25] Kim BK, Kim SU, Choi GH, Han WK, Park MS, Kim EH, et al. "Normal" liver stiffness values differ between men and women: a prospective study for healthy living liver and kidney donors in a native Korean population. J Gastroenterol Hepatol 2012;27:781-788. doi: 10.1111/j.14401746.2011.06962.x.

[26] Chen YP, Liang XE, Zhang Q, Dai M, Hou JL. Age influencing liver stiffness measurements in Chinese male general populations. J Hepatol 2010;52: S162. doi: 10.1016/S0168-8278(10)60397-2. 
[27] Das K, Sarkar R, Ahmed SM, Mridha AR, Mukherjee PS, Das K, et al. "Normal" liver stiffness measure (LSM) values are higher in both lean and obese individuals: a population-based study from a developing country. Hepatology 2012;55:584-593. doi: 10.1002/hep.24694.

[28] Wong GL, Chan HL,Choi PC, Chan AW, Lo AO, Chim AM, et al. Association between anthropometric parameters and measurements of liver stiffness by transient elastography. Clin Gastroenterol Hepatol 2013;11:295-302. doi: 10.1016/j.cgh.2012.09.025.

[29] Marcellin P, Ziol M, Bedossa $P$, Douvin C, Poupon R, de Lédinghen $V$, et al. Non-invasive assessment of liver fibrosis by stiffness measurement in patients with chronic hepatitis B. Liver Int 2009;29:242-247. doi: 10.1111/j.1478-3231.2008.01802.x.

[30] Chan HL, Wong GL, Choi PC, Chan AW, Chim AM, Yiu KK, et al. Alanine aminotransferase-based algorithms of liver stiffness measurement by transient elastography (Fibroscan) for liver fibrosis in chronic hepatitis B. J Viral Hepat 2009:16:36-44. doi: 10.1111/j.1365-2893.2008.01037x.

[31] Viganò $M$, Paggi $S$, Lampertico $P$, Fraquelli $M$, Massironi $S$, Ronchi G, et al. Dual cut-off transient elastography to assess liver fibrosis in chronic hepatitis B: a cohort study with internal validation. Aliment Pharmacol Ther 2011;34: 353-362. doi: 10.1111/j.1365-2036.2011.04722.x.

[32] Jia JD, Hou JL, Ding HG, Chen JM, Xie Q, Wang YM, et al. Liver stiffness measured by transient elastography can predict liver fibrosis in Chinese patients with chronic hepatitis B. Hepatol Int 2010;4:22.

[33] Chen YP, Liang XE, Zhang $Q$, Peng J, Zhu YF, Wen WQ, et al, Larger biopsies evaluation of transient elastography for detecting advanced fibrosis in patients with compensated chronic hepatitis B. J Gastroenterol Hepatol 2012;27:1219-1226. doi: 10.1111/j.1440-1746.2012.07122.x.

[34] Kim SU, Kim do Y, Park JY, Lee JH, Ahn SH, Kim JK, et al. How can we enhance the performance of liver stiffness measurement using FibroScan in diagnosing liver cirrhosis in patients with chronic hepatitis B? J Clin Gastroenterol 2010;44:66-71. doi: 10.1097/MCG.0b013e3181a95c7f.

[35] Kim BK, Kim SU, Kim HS, Park JY, Ahn SH, Chon CY, et al. Prospective validation of FibroTest in comparison with liver stiffness for predicting liver fibrosis in Asian subjects with chronic hepatitis B. PLoS One 2012;7:35825. doi: $10.1371 /$ journal.pone.0035825.

[36] Cardoso AC, Carvalho-Filho RJ, Stern C, Dipumpo A, Giuily N, Ripault MP, et al. Direct comparison of diagnostic performance of transient elastography in patients with chronic hepatitis B and chronic hepatitis C. Liver Int 2012; 32:612-621. doi: 10.1111/j.1478-3231.2011.02660.x

[37] Castéra L, Le Bail B, Roudot-Thoraval F, Bernard PH, Foucher J, Merrouche W, et al. Early detection in routine clinical practice of cirrhosis and oesophageal varices in chronic hepatitis C: comparison of transient elastography (FibroScan) with standard laboratory tests and non-invasive scores. J Hepatol 2009;50:59-68. doi: 10.1016/j.jhep.2008.08.018.

[38] Ziol M, Handra-Luca A, Kettaneh A, Christidis C, Mal F, Kazemi F, et al. Noninvasive assessment of liver fibrosis by measurement of stiffness in patients with chronic hepatitis C. Hepatology 2005;41:48-54. doi: 10.1002/ hep. 20506.

[39] Ferraioli G,Tinelli C, Dal Bello B, Zicchetti M, Lissandrin R, Filice G, et al. Performance of liver stiffness measurements by transient elastography in chronic hepatitis. World J Gastroenterol 2013;19:49-56.

[40] Wong VW, Vergniol J, Wong GL, Foucher J, Chan HL, Le Bail B, et al. Diagnosis of fibrosis and cirrhosis using liver stiffness measurement in nonalcoholic fatty liver disease. Hepatology 2010;51:454-462. doi: 10.1002/hep.23312.

[41] Wong GL, Wong VW, Choi PC, Chan AW, Chim AM, Yiu KK, et al. On-treatment monitoring of liver fibrosis with transient elastography in chronic hepatitis $B$ patients. Antivir Ther 2011;16:165-172. doi: 10.3851/IMP1726.

[42] Roulot D, Costes JL, Buyck JF, Warzocha U, Gambier N, Czernichow S, et al. Transient elastography as a screening tool for liver fibrosis and cirrhosis in a community-based population aged over 45 years. Gut 2011;60:977-984. doi: 10.1136/gut.2010.221382.

[43] Masuzaki R, Tateishi R, Yoshida H, Goto E, Sato T, Ohki T, et al. Prospective risk assessment for hepatocellular carcinoma development in patients with chronic hepatitis C by transient elastography. Hepatology 2009;49:19541961. doi: 10.1002/hep.22870.

[44] Jung KS, Kim SU, Ahn SH, Park YN, Kim do Y, Park JY, et al. Risk assessment of hepatitis B virus-related hepatocellular carcinoma development using liver stiffness measurement (FibroScan). Hepatology 2011;53:885-894. doi: $10.1002 /$ hep. 24121 .

[45] Foucher J, Chanteloup E, Vergniol J, Castéra L, Le Bail B, Adhoute X, et al. Diagnosis of cirrhosis by transient elastography (FibroScan): a prospective study. Gut 2006;55:403-408. doi: 10.1136/gut.2005.069153.

[46] Chen YP, Liang XE, Zhang Q, Dai L, Peng J, Hou JL. Transient elastography accurately predicts the severity of disease in patients with chronic hepatitis B. Chin J Intern Med 2011;50:758-762. (in Chinese)

[47] Chen YP, Zhang Q, Dai L, Liang XE, Peng J, Hou JL. Is transient elastography valuable for high-risk esophageal varices prediction in patients with hepatitis-B-related cirrhosis? J Gastroenterol Hepatol 2012;27:533-539. doi: $10.1111 /$ j.1440-1746.2011.06889.x.

[48] Pineda JA, Recio E, Camacho A, Macías J, Almodóvar C, González-Serrano M, et al. Liver stiffness as a predictor of esophageal varices requiring therapy in HIV/hepatitis C virus-coinfected patients with cirrhosis. J Acquir Immune Defic Syndr 2009;51:445-449. doi: 10.1097/QAI.0b013e3181acb675.

[49] Wang JH, Chuah SK, Lu SN, Hung CH, Chen CH, Kee KM, et al. Transient elastography and simple blood markers in the diagnosis of esophageal varices for compensated patients with hepatitis B virus-related cirrhosis. J Gastroenterol Hepatol 2012;27:1213-1218. doi: 10.1111/j.14401746.2012.07132.x.

[50] Kim BK, Kim do Y, Han KH, Park JY, Kim JK, Paik YH, et al. Risk assessment of esophageal variceal bleeding in B-viral liver cirrhosis by a liver stiffness measurement-based model. Am J Gastroenterol 2011;106:1654-1662. 